\title{
STRUCTURAL ANALYSIS OF HISTORICAL CONSTRUCTIONS BY GRAPHIC METHODOLOGIES BASED ON FUNICULAR AND PROJECTIVE GEOMETRY
}

\author{
JAVIER SUÁREZ ${ }^{1 *}$, THOMAS BOOTHBY ${ }^{2}$ and JOSE ANTONIO GONZÁLEZ ${ }^{3}$ \\ ${ }^{1}$ Department of Mechanic of Structures and Hydraulic Engineering. University of Granada. SPAIN \\ Edificio politécnico, Campus Fuentenueva s/n 18001 Granada, Spain \\ e-mail: fjsuarez@ugr.es, https://meih.ugr.es/ (*corresponding author) \\ ${ }^{2}$ Department of Architectural Engineering, Penn State University, PA, US. \\ 104 Engineering Unit A, The Pennsylvania State University, University Park, PA 16802 \\ e-mail: teb2@psu.edu - web page: https://www.ae.psu.edu/ \\ ${ }^{3}$ International Graduate School. University of Granada. Spain. \\ C/ Paz, 1818071 Granada, Spain. email: jogocaar@ugr.es
}

Keywords: historical structure, structural analysis, limit analysis; funicular geometry, projective geometry.

\begin{abstract}
This paper presents a graphic methodology for the structural analysis of domes and other surfaces of revolution, based on a combined use of funicular and projective geometry. By considering a dome as a network of lines of latitude and longitude, the equilibrium of the network is analyzed in both horizontal and vertical projection. The resulting dual configuration is also a spatial system that can be considered by its projection in a horizontal and a vertical plane.

The dome is divided by latitude and longitude into an arbitrary number of sectors, and the equilibrium is enforced at each node. The tangential forces can be considered for their net effect at each node; the net effect of two tangential forces, equal in magnitude, at a node is a radially directed force in the plane of the line of latitude, acting outwards (compression) or inwards (tension).

Considering their horizontal projection, and its dual form, it is possible to choose the shape of the radial force diagram (the vertical projection and the force diagram), and identify the radial forces associated with it, and thus the tangential forces.

The new methodology is presented through its application to a hemispherical brick dome of small thickness.

The hemispherical brick dome has been also analyzed by applying the slicing technique, considering different hypotheses regarding the structural behavior of the haunch filling, according to its morphological characterization.

The structural analysis of the brick dome using both methodologies allows us to contrast the results obtained.
\end{abstract}

\section{INTRODUCTION}

This paper presents a new graphic methodology for the structural analysis of domes and other surfaces of revolution, based on a combined use of funicular and projective geometry. 
The new methodology is presented through its application to a hemispherical brick dome of small thickness.

The model used refers to a real dome: the hemispherical brick dome over the transept, in Basilica of San Juan de Dios in Granada (Spain), (figure1). The constructive analysis of the dome was laid out by the authors in [1].

The hemispherical brick dome has been also analyzed by applying the slicing technique, considering different hypotheses regarding the structural behavior of the haunch filling, according to its morphological characterization.

The structural analysis of the brick dome using both methodologies allows us to contrast the results obtained.

\section{STRUCTURAL ANALYSIS OF DOMES BY EQUILIBRIUM METHODS}

The first contribution to the structural analysis of domes corresponds to Bouguer [2], which solves the theoretical problem of finding the ideal form of a dome, that is the mathematical equation of the curve which, by revolution, can generate a stable dome, considering the hypothesis that there is no friction between the segments.

Frézier 's stereotomy treatise [3] dedicates a full chapter to the thrust of vaults and divides their study in simple (barrel vaults and lintel vaults) and compound (spherical, ribbed vaults, cloister corner, etc.). Frézier does not analyze specific examples, but he specifies how this analysis should be carried out. He considers the vaults composed of elementary arches, and compares their thrust with the barrel vaults one, which he considers to be known; it is a first version of what is now known as the slicing technique.
The first studies on the stability of existing domes are carried out in the $1740 \mathrm{~s}$, commissioned
by Pope Benedict XIV, on the occasion of the damages observed in the dome of St. Peter of
Rome.
The first study was made by three mathematicians, Le Seur, Jacquier and Boscovich in $1 / 42$

[4]. These authors, based on the location of the cracks and the analysis of the movement allowed

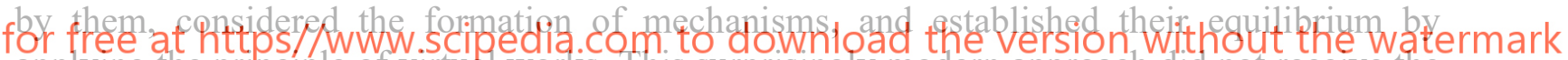
applying the principle of virtual works. This surprisingly modern approach did not receive the attention it deserved and had no subsequent referrals.

\section{Slicing technique}

The second study was conducted by Poleni in 1743 and published in 1748 [5]. Poleni, after making a critical examination of the theories known to date on the stability of the vaults, discards the approach of the three mathematicians, and decides to use the slicing technique, by making a model and considering the theory of the catenary.

The slicing technique consists in considering the dome divided into segments, cutting by meridian planes. Every two opposite segments form an arc. If it is possible to draw a thrust line contained in the thickness of the arc, a possible state of equilibrium of the arch in compression has been found; then the arch is stable, and so is the dome. The brilliant analysis of Poleni barely had any subsequent consequences until the second half of the 19th century.

In the second half of the 18th century, regarding the debate on the stability of the dome of Santa Genoveva in Paris, it is noteworthy the theoretical studies carried out by Gauthey [6] and the experiences on Rondelet models (1802).

In the first half of the 19th century, in the context of l'École Polytechnique, l'École des Ponts et Chaussées, and the development of the Elasticity Theory, the first rigorous analytical contributions appeared. In 1826 Navier, in his lesson book of Résistance des Matériaux, [7], 
includes theoretical assumptions for the analysis of domes, groin vaults and cloister vaults. However, the contributions are always theoretical or limited to the verification of the stability of a specific dome or vault.

\section{Graphic methods}

In the second half of the 19th century the usual methodology to verify the structural stability of domes was the slicing technique and the manufacture of models with catenaries.

Jean-Victor Poncelet, director engineer of l'École Polytechnique, had published his book Traité des propriétés projectives des figures [8], in which he developed projective geometry from the work of Gérard Desargues in the 17th century.

Inspired by the work of Poncelet, Karl Culmann publishes his seminal book Graphic Statics [9], which meant the appearance of Graphic Static, with enormous influence on the engineers at the time, Maurice Koechlin, Otto Mohr, and Luigi Cremona.

Incorporating Graphic Static to the slicing technique allows the analysis of any type of vault and historical construction, however complex it may be. The analysis of almost all the vaults used in historical architecture can find in [10]

In the early $1900 \mathrm{~s}$, graphic methods were widely used to verify previously projected forms following traditional rules of proportion.

The Spanish architect Antoni Gaudí used the graphic methods, not only to analyze already defined projects, but to design using balanced catenary forms.

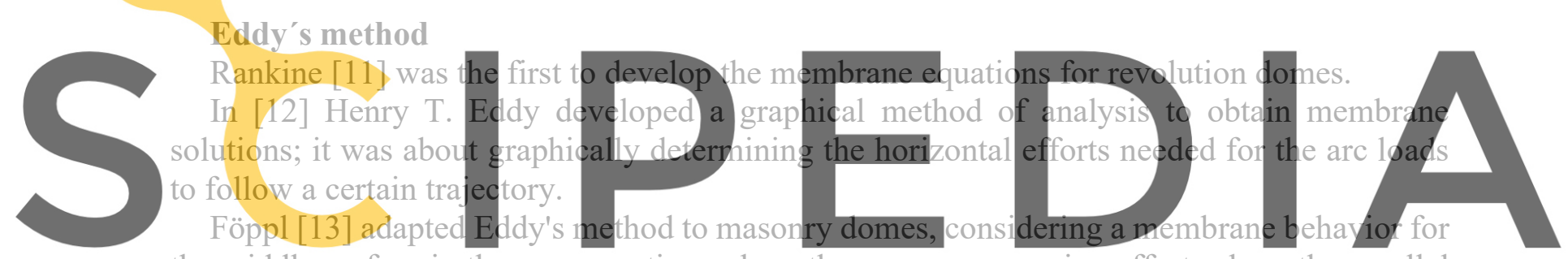

the middle surface in the upper section, where there are compression efforts along the parallel

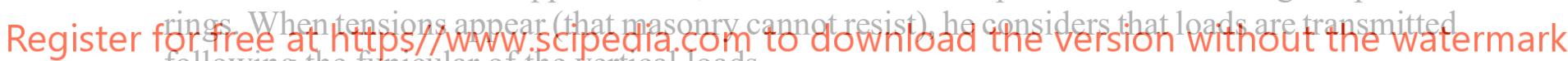
following the funicular of the vertical loads.

Eddy's method became popular thanks to Dunn's publications [14], [15].

In 1909 Rafael Guastavino Jr. applied Eddy's method to calculate a large brick dome on the transept of the Cathedral of St. John the Divine, in New York.

These equilibrium methods were considered approximate by the engineers of that time, who were strongly conditioned by the elastic theory. Although it was possible to analyze an elastic arc, the elastic analysis of spatial structures was beyond the scope of manual calculation. After World War II there was the need to analyze the vaults and ruined buildings before their reconstruction, therefore graphic equilibrium analysis methods were again used; this is the case, for example, of the vaults of the Cathedral of Xanten and of numerous churches and buildings rebuilt by Pieper [16].

In the second half of the 20th century, Heyman [17], [18] presented for the first time the slicing technique and its application in masonry structures, within the theoretical framework of Limit Analysis.

When considering the dome divided into segments by cuts along meridian planes, the slicing technique does not consider the influence of parallel forces on the stability of the dome. 


\section{BRICK HEMISPHERICAL DOME}

This paper presents a new graphic methodology based on combining projective and funicular geometry, for the quantitative determination of efforts in revolution domes, from equilibrium considerations of parallel and meridian efforts.

This methodology is presented through its application to a brick thin dome. The stability of this dome is also assessed with the slicing technique, allowing to contrast the results.

The model considered refers to a real one: the brick dome over the transept in Basilica of San Juan de Dios in Granada (Spain), (figure1).

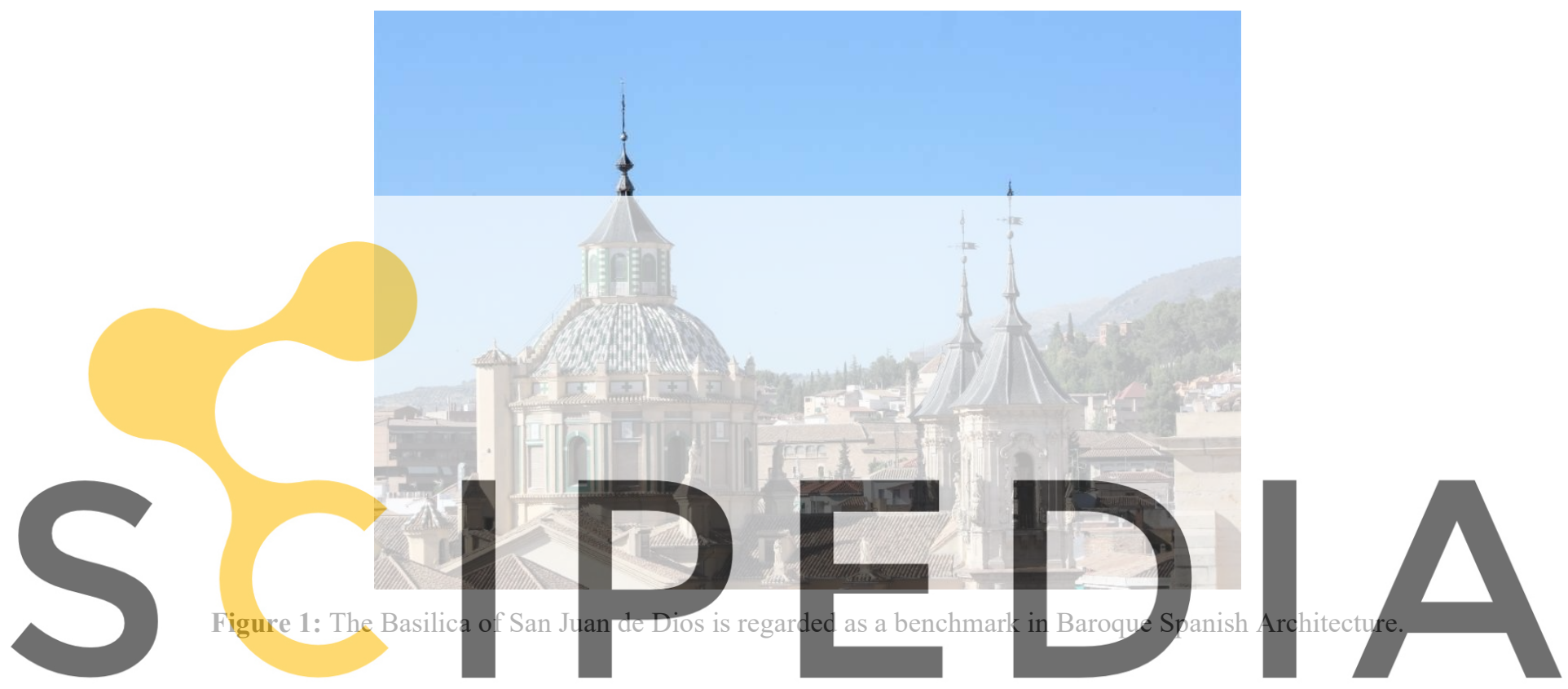

The dome of San Juan de Dios" Basilica was designed and built as an "encamonada dome",

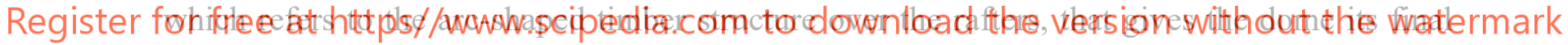
outer shape. This typology was implemented in accord with the directions of Fray Lorenzo de San Nicolás's treatise, [19].

Figure 2 shows the following constructive elements of the dome:

- Brick masonry drum, $11.71 \mathrm{~m}$ inner diameter, $1.73 \mathrm{~m}$ in thickness and $6.7 \mathrm{~m}$ height.

- Inner dome with double brick layer, of $8 \mathrm{~cm}$ thickness. The dome is built with brick of 3 $\mathrm{cm}$ thickness, the bricks were laid in sailor position (with the bed visible). The dome is bearing its own weight $\left(1.4 \mathrm{kN} / \mathrm{m}^{2}\right)$.

- Filling of the haunch up to $1 / 3$ of the radius of the dome.

- Supporting elements: in the top of the drum masonry wooden elements are embedded, and wooden mudsills are superimposed.

- Wooden structure: formed by curved beams (camones) resting on wooden mudsill.

- Planking: $3 \mathrm{~cm}$ thick wooden boards nailed on the arches centering, creating a flat surface for the roof tiles, bracing the "camones" and providing a monolithic structure.

- Bonding mortar coat on the planking.

- White and green glazed ceramic roof tiles, on the mortar layer.

The drum of the lantern is made of brick and rests on the wooden structure. Inside the lantern, there is a single layer of brick with which the inner curved surface is achieved. The lantern is surmounted with a spire similarly to the towers. [20]. 
The structural analysis of the dome through two methodologies, and the contrast of the results obtained, is presented in the following sections.

\section{STABILITY ANALYSIS BY APPLYING THE SLICING TECHNIQUE}

The stability of the inner brick dome is analyzed by applying the slicing technique developed by Heyman [21] \& [22]. The suitability of this methodology to assess the stability of timbrel domes is discussed in [23] and [24].

To apply the theory of Limit Analysis, the following assumptions of masonry behavior are made:

- The material does not have tensile strength.

- For practical purposes, the material can be considered to have unlimited compressive strength.

- $\quad$ Sliding between masonry blocks cannot occur.

If this is the case, the safe theorem establishes that the masonry will be stable if it is possible to find a line of thrust, in equilibrium with the loads, which is entirely included within the section of the masonry.

The geometric safety factor is defined by the ratio between the actual thickness and the minimum thickness of the masonry required to contain the thrust line.

For the current analysis, the dome is divided into fifty spherical spindles (lunes or slices); by checking the stability of each sector, the stability of the entire dome is guaranteed.

Due to symmetry, only one half of each sector is considered. Each sector is considered

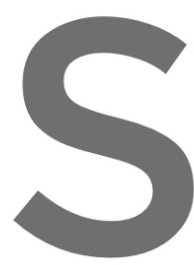

divided into 19 youss pi

The stability of the

dome with external filli

In [25] the structura

morphological characterizatio
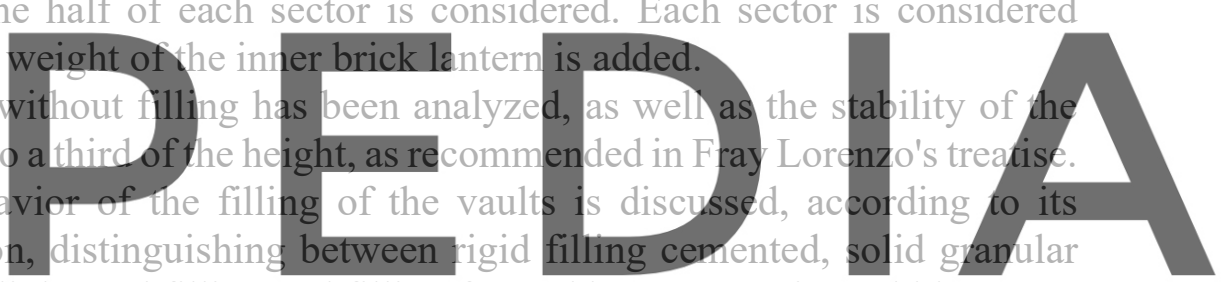

filling, loose granular filling, lightened filling and filling formed by construction rubble.

Register for If this panet thrye hypothesses of backfil structural beha vior are considered (figure 3 ): watermark

Hypothesis 1: The filling is made of loose granular material. It has no structural behavior

and is considered a dead load on the dome. This hypothesis is modelled by incorporating weights of the filling volumes into the force system, without increasing the section.

Hypothesis 2: The filling is of firm granular material and therefore has a structural function. This hypothesis is modelled by increasing thickness of voussoirs located in the lower third of the height.

Hypothesis 3: The filling is rigidly cemented, preventing the movement of the voussoirs. This hypothesis has been analyzed considering the dome as a shallow dome.

In all cases the weight of the inner brick coating of the lantern was also considered. Thus, four different structural situations have been considered. Each one has been analyzed, by considering different positions of the thrust in the keystone and the reaction in the springer; for each position, the line of thrust has been graphically determined to find a geometry of the line of thrust, in equilibrium with the loads, that is entirely within in the masonry section.

Figure 4 shows the graphical constructions of the thrust line for the hypotheses 2 and 3, considering the weight of the inner brick coating of the lantern. 


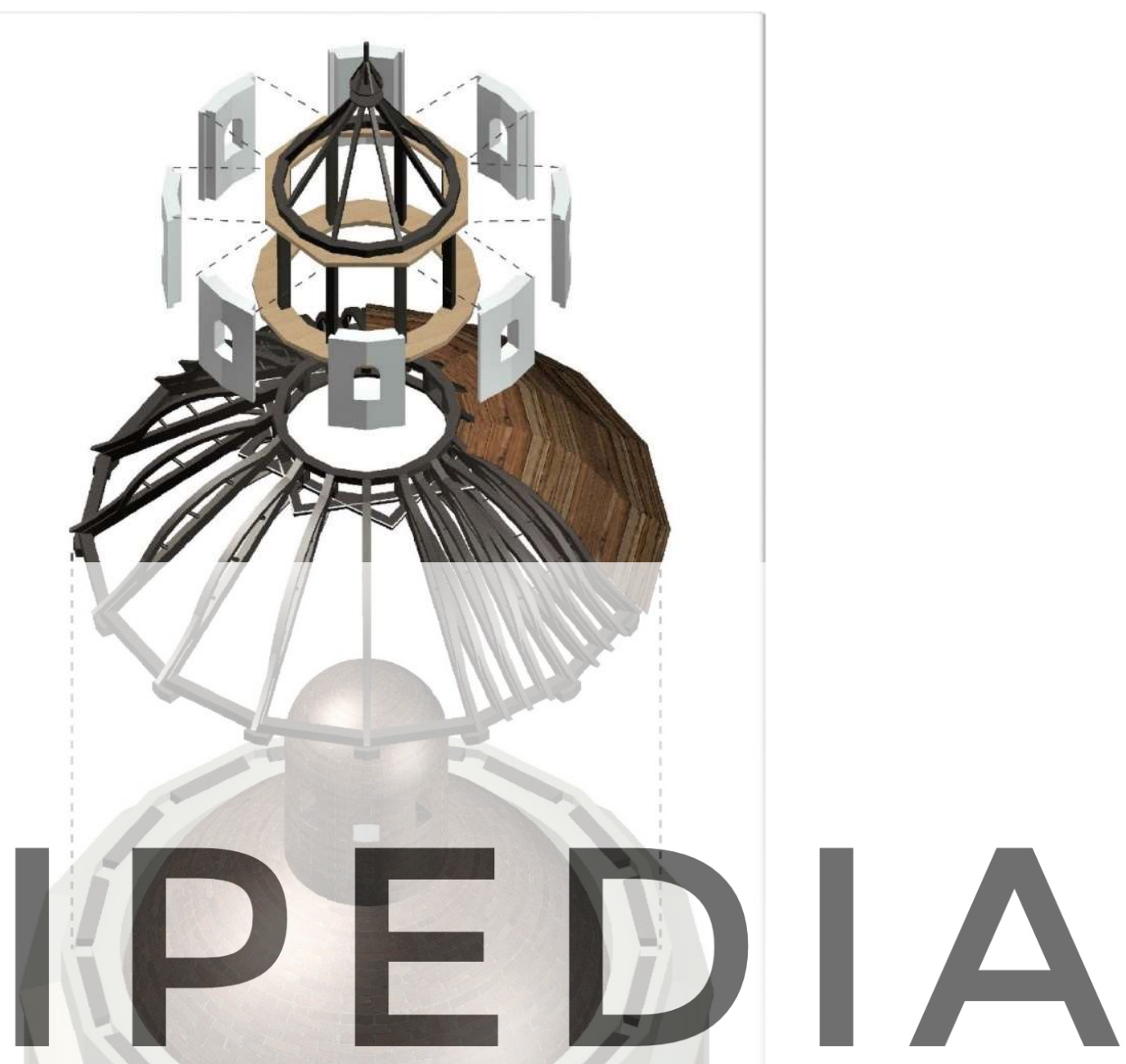

Register for free at https//www.scipedia.com to download the version without the watermark

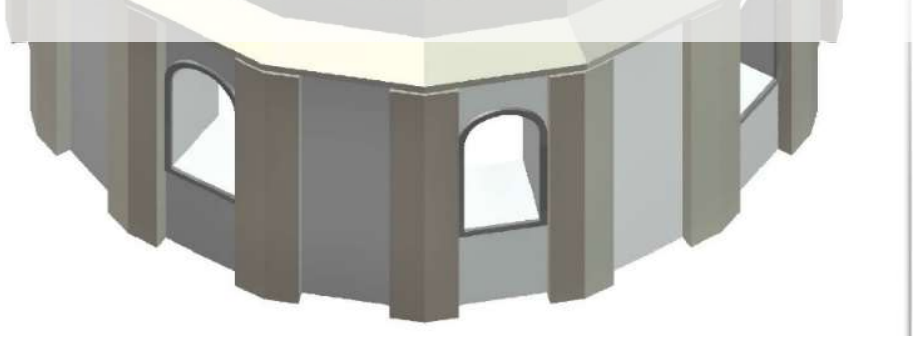

Figure 2. Three-dimensional model of the dome shows how the inner brick coating of the lantern is attached to the brick dome.

Only in hypotheses 2 and 3 and considering the weight of the inner brick coating of the lantern, have resulted a geometry of the thrust line in equilibrium with the loads that is also within the section of the dome masonry. This highlights the importance in the stability of the timbrel dome, of the filling up to one third of the height, as recommended by Fray Lorenzo de San Nicolás. 


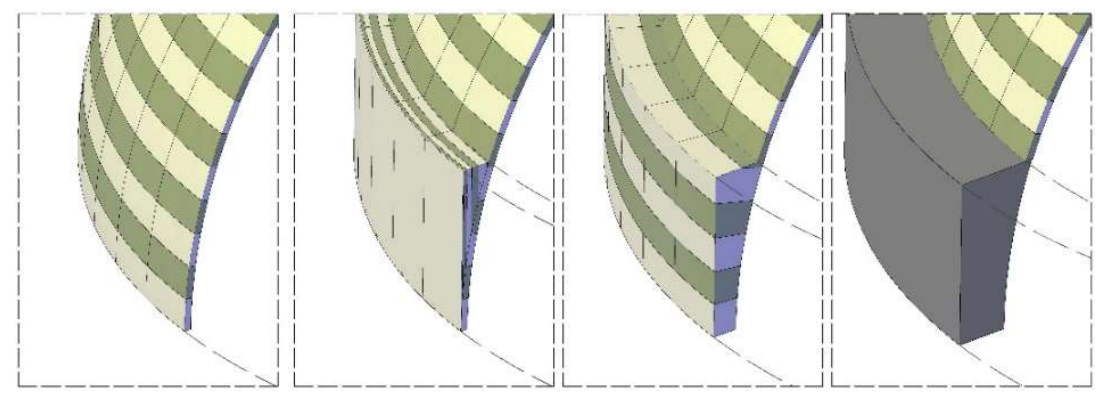

Figure 3. Four hypotheses of structural behavior of filling in the extrados of the dome, have been considered. From left to right; (a) without filling; (b) filling of loose granular material, without structural behavior; (c) filling of firm granular material, with structural function; (d) cemented rigid filling acting as embedment considered as a shallow dome.
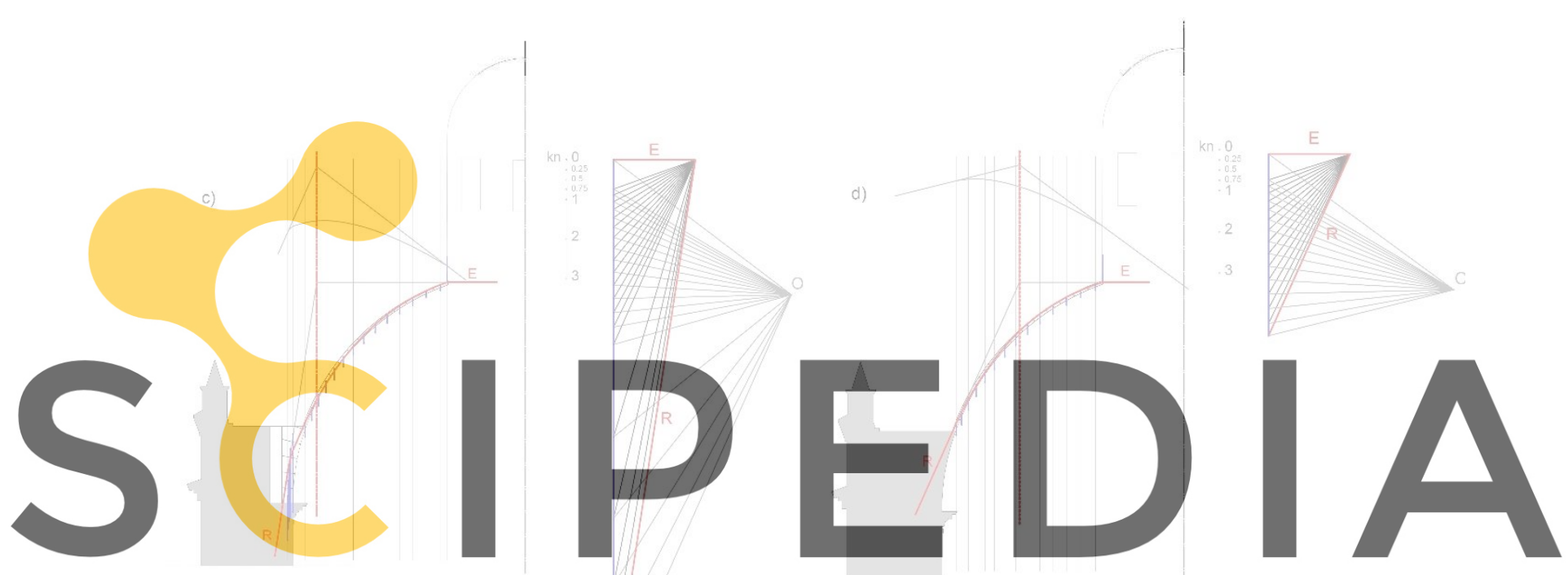

Register for free at https//www.scipedía.com to download the version without the watermark

Figure 4. The figure on the left shows' hypothesis 2: filling of firm granular material with structural function. Considering the weight of the lantern, and the horizontal thrust in the keystone located at the top point of the section, and the reaction in the springer $9 / 10$ on the outside of the impost, the position of the line of thrust contained inside the section of the masonry with a geometric safety factor equal to 1.09 , a maximum value of compression effort of $13.5 \mathrm{kN}$ is obtained. The figure on the right shows' hypothesis 3: cemented rigid filling, preventing the movement of the masonry. It is considered a shallow dome. Considering the horizontal thrust in the keystone at the $4 / 5$ top point of the section and the reaction in the springer at 5/6 outside the impost, the thrust line located inside the masonry is determined, with a geometric safety factor equal to 1.28 ; a maximum value of compression effort of $4.8 \mathrm{kN}$ is obtained.

\section{GRAPHIC METHODOLOGIES BASED ON FUNICULAR AND PROJECTIVE GEOMETRY.}

In this section, a new method is developed for the graphical analysis of domes and other surfaces of revolution, based in Thrust-Network Analysis presented in [26], incorporating other notions from projective geometry to make a more comprehensive method for the analysis of certain classes of structure.

In [26], the forces in a spatial network are solved by the graphical analysis of their horizontal projection: equilibrium of the spatial system is preserved in the plane system. The forces are 
analyzed within a dual system in which the forces in equilibrium at each joint are represented by a closed polygon.

In the following, the dome is considered as a network of lines of latitude and longitude; the equilibrium of this network is analyzed in both horizontal and vertical projection. The resulting dual configuration is also a spatial system that can be considered by its projection in a horizontal and a vertical plane. This procedure not only allows the solution of the forces in a system for a given configuration, but also allows an inverse solution of the internal forces that result in a given shape.

The dome is divided by latitude and longitude into an arbitrary number of sectors [figure 5]. Equilibrium can be enforced at each node, that is, at each intersection of latitude and longitude lines. In keeping with [27], [14], [15] and [12], it is noted that the tangential forces can be considered for their net effect at each node: the net effect of two tangential forces, equal in magnitude, at a node is a radially directed force in the plane of the line of latitude: acting outwards (tangential compression) or inwards (tangential tension).

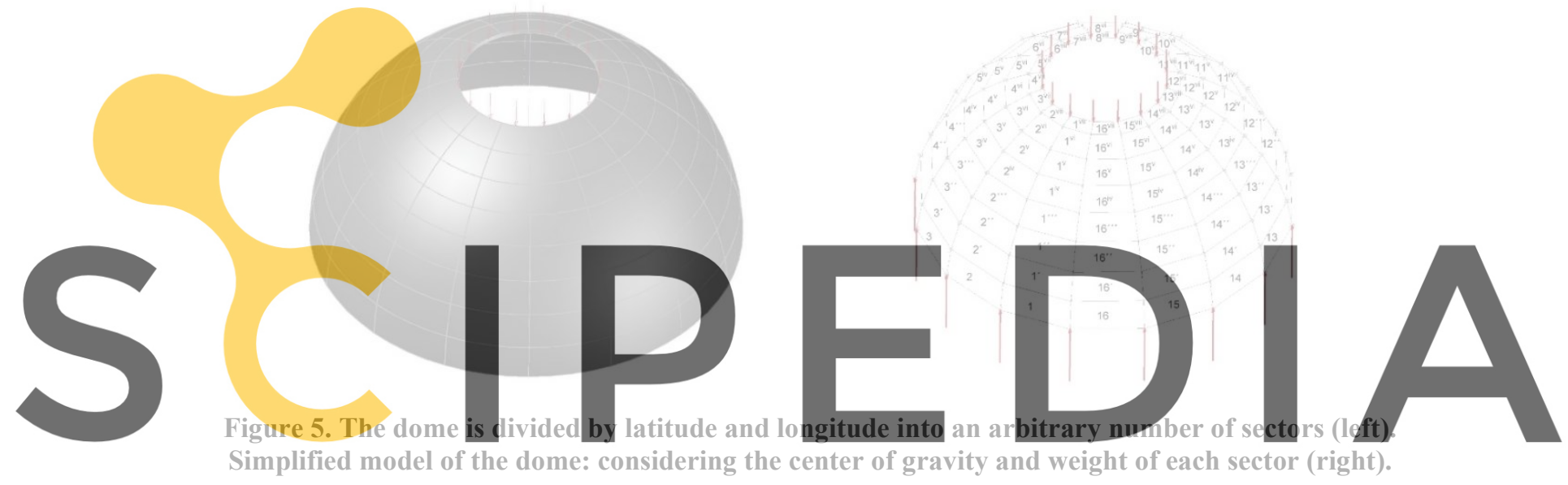

Register for free at https//www.scipedia.com to download the version without the watermark The lines of longitude and latitude project in a plane through the equator to form a network of forces, as in [26]. These plane forces can be considered in their dual form, which is a similar figure (force polygon) with all of the characteristics reversed: tangential lines on the primal figure are represented by their net radial force in the dual figure, while the radial forces in the primal figure appear as tangential lines in the dual figure. The forces at the exterior of the dome in the primal figure are represented by the center point of the interior of the dual figure, while the forces at the apex of the dome are represented by the lines on perimeter of the dual figure.

Figure 5 represents a simplified model of the dome. The longitude and latitude lines represent the network of discretized membrane forces, in horizontal and vertical projection (figure 6). The spaces between these funicular lines are numbered using Bow's notation; [28].

Figure 7 shows the forces associated with these lines. Each node in the primal system is represented by a quadrilateral of forces in the dual force diagram. Although, sector by sector, the horizontally projected force diagram resembles the funicular diagram, they are different. It is particularly noteworthy that the location distance of the radial forces (represented as tangential lines) from the pole on the dual figure is arbitrary, indicating the high degree of statical indeterminacy of the dome under analysis. On the horizontal projection of the force diagram, on the dual figure, a statically admissible solution can be constructed with practically any position of the ring of radial forces; inward or outward movement of this ring signifies increased or decreased tangential forces. 

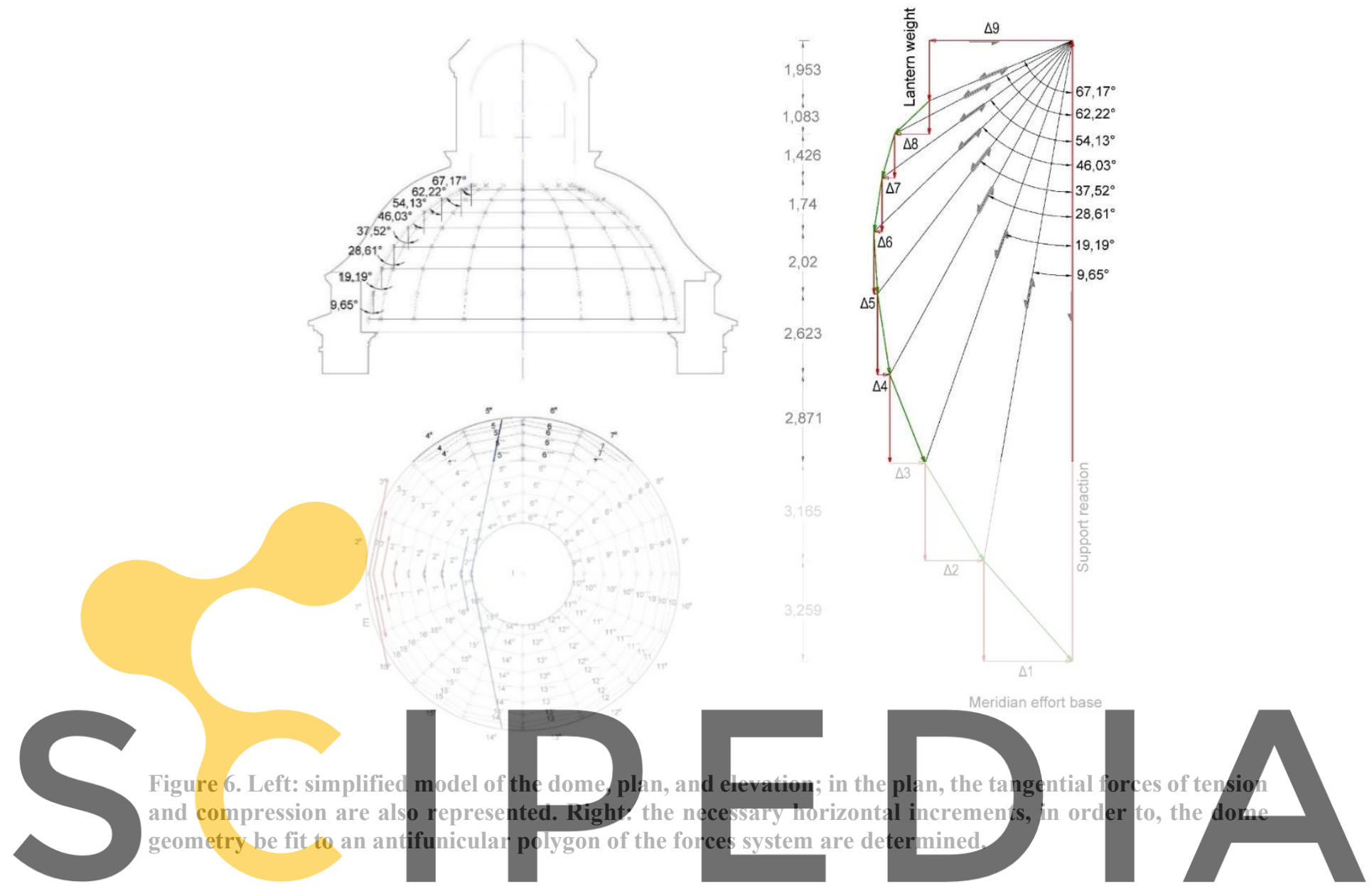

On the other hand, by an inverse procedure, as shown in Figures 6 and 7, it is possible to

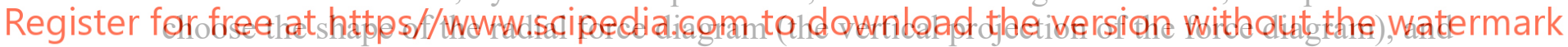
identify the radial forces associated with it, and thus the tangential forces. This is illustrated in figure 6, where the meridional forces in the dome are shown. The horizontal components of these forces at each node are related to the tangential force components. The angles of the polar rays are chosen so that this polygon matches the shape of the dome exactly. The horizontal forces in the meridional section and hence the tangential forces at each level in the dome are chosen to maintain the proper angles in the funicular polygon. As shown, there is a multiplicity of possible solutions that give exactly this force distribution.

The equilibrium in the vertical plane is assured, by fitting the forces' polygon to the polar rays, so then the dome geometry is an antifunicular of the forces system. The equilibrium of nodal efforts in the horizontal plane is assured by taking the values of the transversal forces from the dual figure.

The result is the construction of a funicular polygon that follows the shape of the dome exactly.

The values obtained by applying of the graphic methodology proposed, measured in Figure 7, are the following:

- $\quad$ maximum value of tension parallel force (fig. $\left.7, F_{1 \mathrm{e} 1}=F_{2 \mathrm{e} 2}\right): 7.36 \mathrm{kN}\left(0.09 \mathrm{~N} / \mathrm{mm}^{2}\right)$.

- maximum value of compression parallel force: (fig.7, $\left.\mathrm{F}_{1 \text { vii }}=\mathrm{F}_{2 \mathrm{vii}}\right)$ : $11.89 \mathrm{kN}(0.22$ $\left.\mathrm{N} / \mathrm{mm}^{2}\right)$. 
- maximum value of meridian force (fig. 6 right): $17.12 \mathrm{kN}\left(0.09 \mathrm{~N} / \mathrm{mm}^{2}\right)$

In [29] it is considered usual values of brick strength: compressive strength: $15 \mathrm{~N} / \mathrm{mm}^{2}$; tension strength: $1 \mathrm{~N} / \mathrm{mm}^{2}$. In [30] it is exposed that Van der Pluijm [31] used tensile strength values of the masonry unit ranging from 1.5 to $3.5 \mathrm{~N} / \mathrm{mm}^{2}$. Therefore, the values obtained are acceptable for the material.
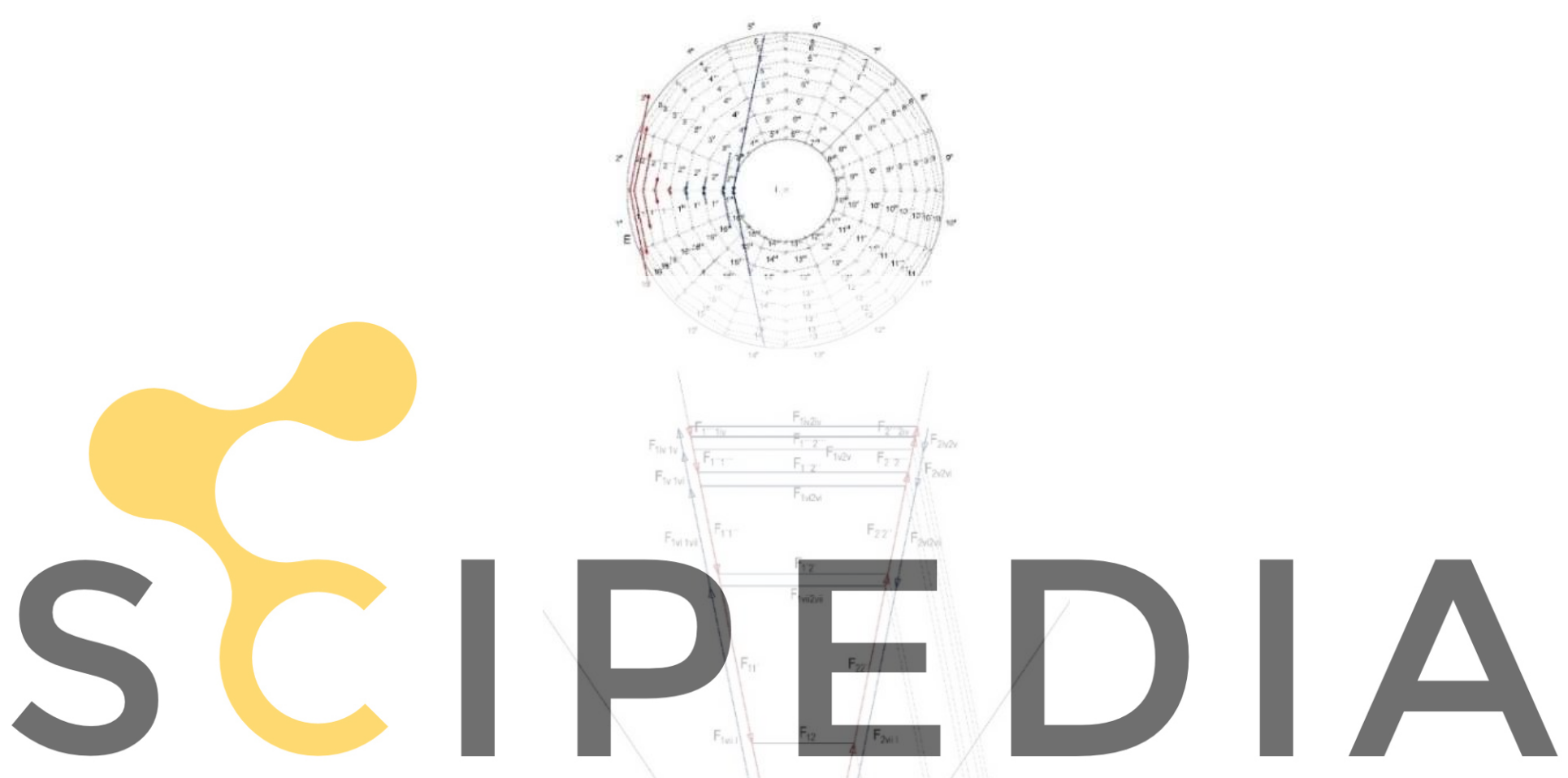

Register for free at https//www.scipedia.com to download the version without the watermark

Figure 7. Dual figure: from calculated values of increments, the values of tangential forces in the dome are determined.

\section{CONCLUSIONS}

This paper presents a new graphic methodology for the structural analysis of domes and other surfaces of revolution, based on combining funicular and projective geometry. It is a new methodology, still in the early stages of its development.

This methodology is presented through its application to a brick dome thin. The stability of this dome is also assessed with the slicing technique, allowing to contrast the results. 
The application of the slicing technique, in the frame of limit analysis theorems is a wellknown and contrasted technique for the stability analysis of domes, which does not consider the tangential forces. In this work, the results of this analysis highlight the importance in the stability of the timbrel dome of the filling up to one third of the height, as recommended by Fray Lorenzo de San Nicolás.

This new graphic methodology takes into account the tangential forces to determine equilibrium forces solutions in the dome. This equilibrium solution represents one admissible stress state for the dome and leads us to belief that the backfilling of the intrados could be unnecessary.

\section{REFERENCES}

[1] Suarez Medina, F.J, Bravo Pareja, R., González Casares, J. A., Structural and Constructive Analysis of a Faux Vault, the Dome of San Juan de Dios Church, in Granada (SPAIN). International Journal of Architectural Heritage. (2019). https://doi.org/10.1080/15583058.2019.1645242.

[2] Bouguer, P., Sur les lignes courbes qui sont propres à former les voûtes en dôme. Mémoires de l'Académie Royale de Sciences de Paris, (1734), 149-66.

[3] Frézier, A. F., La théorie et la pratique de la coupe des pierres et des bois, pour la construction des voûtes... ou Traité de stéréotomie à l'usage de l'architecture (Vol.1). JeanDaniel Doulsseker. (1737).

[4] Le Seur, T., Jacquier, F., \& Boscovich, R. G. Parere di Tre Matematici Sopra i danni, che si sono trovati nella cupola di San Pietro. (1742).

[5] Poleni, J. Memorie istoriche della gran cupola del tempio Vaticano e de'danni di essa e detristoramenti loro, divisi in libri 5. Nella Stamperia del seminario. (1748).

[6] Gauthey, E. M., Mémoire sur l'application des principes de la mécanique a la construction des voutes et des dômes, dans lequel on examine le problème proposé par M. Patte, relativement a la construction de la coupole de l'église Sainte-Geneviève de Paris. Par M. Gauthey de l'imprimerie de louis-Nicolas Frantin. (1771).

[7] Navier, C. L. M. H., Résumé des leçons données à l'école royale des Ponts et chaussées sur l'application de la mécanique à l'établissement des constructions et des machines (Vol. 1). Didot. (1826).

[8] Poncelet, J., Traité des propriétés projectives des figures, deux volumes. Bachelier, Paris, 2. (1822).

[9] Culmann, K., Die Graphische Statik, Meyer und Zeller. Zürich. (1865).

[10] Körner, C., "Gewölbte Decken." Handbuch der Architectur, Third part 2 (1901): 141-553.

[11] Rankine, W. J. M., A Manual of Applied Mechanics. Charles Griffin, London (1858).

[12] Eddy, Henry T., Research in Graphical Statics, New York, Van Nostrand. (1878).

[13] Föppl, A., Ausgewählte Capitel der mathematischen Theorie der Bauconstructionen. 1. Theorie der Gewölbe: mit vier Tafeln und vielen Holzschnitten. (1881).

[14] Dunn, W., Notes on the stress in Framed Spires and Domes. Journal of the Royal Institute of British Architects. Third Series, vol. 11; (1904). 401- 412.

[15] Dunn, W., The Principles of Dome Construction. Architectural Review. (1908). Vol 23: 63-73; 108-112.

[16] Pieper, K., Sicherung historischer Bauten. W. Ernst, (1983).

[17] Heyman, J., "On shell solutions of masonry domes". International Journal of Solids and Structures, vol. 3, (1967), pp 227.

[18] Heyman, J., Equilibrium of shell structures. Oxford University Press, (1977). 
[19] Fray Lorenzo de, S.N., Arte y uso de arquitectura, Madrid, (1639) first book; (1665) second book.

[20] Isla Mingorance, E., José de Bada y Navajas, arquitecto andaluz (1691-1755). Granada, (1977).

[21] Heyman, J., The Stone Skeleton. International Journal of Solids and Structures, 2 (2) (1966) 249-279.

[22] Heyman, J., The Stone Skeleton. Structural Engineering of Masonry Architecture, Cambridge University Press, Cambridge, (1995).

[23] Huerta Fernández, S., La mecánica de las bóvedas tabicadas en su contexto histórico: la aportación de los Guastavino, Las bóvedas de Guastavino en América, Instituto Juan de Herrera. Madrid, (1999).

[24] Redondo Martínez, E., La bóveda tabicada en España en el siglo XIX: la transformación de un sistema constructivo. (PhD Thesis). Polytechnique University of Madrid, (2013).

[25] Ramos León, J., Clasificación morfológica de los rellenos en el trasdós de bóvedas de fábrica. Informes de la Construcción, 65 (532) (2013). 471-480; https://doi.org/10.3989/ic.12.062.

[26] Block, P. \& Ochsendorf, J., Thrust Network Analysis: A new methodology for threedimensional equilibrium. Journal of the international association for shell and spatial structures. Vol. 48. (2007).

[27] Huerta Fernández, S., The Mechanics of Timbrel Vaults: A Historical outline, in Essays on the History of Mechanics, ed. Becchi et al. Basel Birkhauser Verlang. (2003).

[28] Bow, R.H., Economics of construction in relation to frame structures, Spon,

London, (1873).

[29] Huerta Fernández, S., Arcos, bóvedas y cúpulas. Geometría y equilibrio en el cálculo tradicional de estructuras de fábrica, Juan de Herrera Instituto, Madrid, (2004).

[30] Lourenço, P., Experimental and numerical issues in the modelling of the mechanical behavior of masonry. Structural Analysis of Historical Constructions II. Barcelona: P. Roca, J.L. González, E. Oñate and P.B. Lourenço (Eds.) CIMNE. (1998).

[31] Pluijm, V. d., Out of plane bending of masonry: behaviour and strength. doi:10.6100/IR528212. (1999). 